\title{
Study of optical properties of (PMMA) doped by methyl red and methyl
}

\section{blue films}

\author{
Ziad.T. Khodair ${ }^{1}$, Mustafa H. Saeed ${ }^{2}$, Muhammad H. Abdul-Allah ${ }^{1}$ \\ ${ }^{1}$ Department of Physics, College of Science, University of Diyala \\ ${ }^{2}$ Department of Science, College of Basic Education, University of Al- Mustansiriyah \\ E-mail: Muhammadtimimi@yahoo.com
}

\begin{abstract}
The effect of doping by methyl red and methyl blue on the absorption spectra and the optical energy gap of poly (methyl methacrylat) PMMA film have been studied. The optical transmission (T\%) in the wavelength range 190-900 $\mathrm{nm}$ for films deposited by using solvent casting method were measured. The Absorptance data reveals that the doping affected the absorption edge as a red and blue shift in its values. The films show indirect allowed interband transitions that influenced by the doping. Optical constants; refractive index, extinction coefficient and real and imaginary part of dielectric constant were calculated and correlated with doping.
\end{abstract}

Key words

PMMA, optical

properties, red

methyl, blue methyl, interband transitions

\section{Article info.}

Received: Dec. 2012

Accepted: Apr. 2013

Published: Sep. 2014

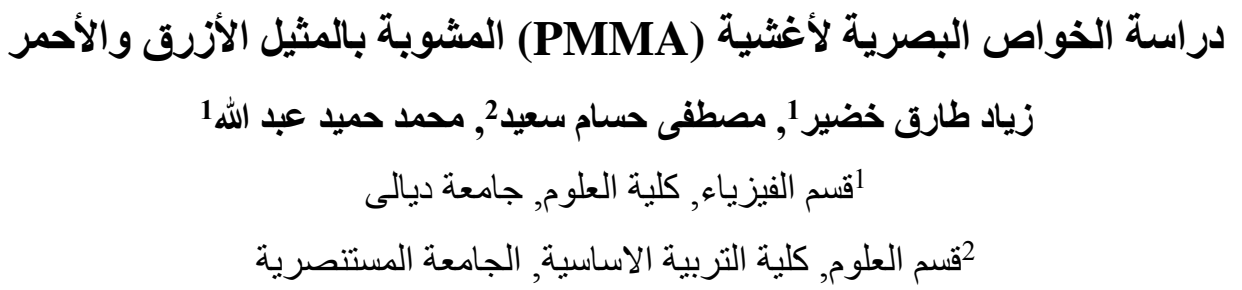

الخلاصة

تم في هذا البحث دراسة تأثير الأشابة بالمثيل الأحمر والمثيل الأزرق على طيف الامتصاص وفجوة الطاقة البصرية لأغشية poly(methyl methacrylat) PMMA. إذ قيست النفاذية البصرية (T\%) ضمن مدى الأطوال الموجية 190-900 nm للأغشية المرسبة بطريقة القولبة. أن نتائج الامتصاصية دلت على أن التثويب أدى إلى الى الانحر اف الأحمر والأزرق في قيمة حافة الامتصاص.وأظهرت الأغثية انتقالات غير مباشرة مسموحة وقد تأثرت بالأثشابة. حسبت الثو ابت البصرية كدالة لنوعية الأشابة مثل معامل الانكسار ، معامل الخمود وثابت العزل بهزئل الأبيه

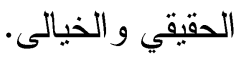

\section{Introduction}

Poly (methyl methacrylate) PMMA has considerable attention in recent year owing to its low cost, good tensile strength, and hardness, high rigidity, transparency, low optical loss in the visible spectrum, low glass temperature, good insulation properties and thermal stability dependent

on tactility[1-3]. Poly methyl methacylatc (PMMA) used in clinical applications[4], and have been widely used due to attractive 
physical and optical properties decisive about its broad applications [5-7]. It can be considered as a good host for organic nano particle due to their high surface to bulk ratio which can significantly affect the properties of PMMA matrix [8,9]. The physical properties of polymers may be affected by doping and thickness. A graft copolymer is a type of branched copolymer with the side chain being different and separate from the main chain. Detailed studies of doped polymer with different dopant concentrations and thickness allow the possibility of choice of the desired properties [10]. On the other hand, methyl red and methyl blue is interesting in terms of optical, electronic and UV-absorbing properties [11].

In this paper an attempt was introduced to obtain the effect of methyl red (mr) and methyl blue (mb) additive on the optical properties of PMMA.

\section{Experimental details}

Poly (methyl methacrylate) of Sigma Aldrich comblt Germany, chloroform (purity of $99.8 \%$ HPLC), was used as a common solvent for both pure PMMA and (methyl red, methyl blue), were dissolved separately in chloroform for 4 hour at room temperature. Appropriate mixtures of PMMA and 7\% weight (red methyl, blue methyl) solutions were mixed. The solution was poured into flat glass plate dishes. Homogenous films were obtained after drying the solution in an oven for 24 hours. The thickness of the prepared films was in the range of $25 \pm 1 \mu \mathrm{m}$.

The absorbance and transmittance spectra were recorded using double bean schimadzu UV/VIS-160A in the wavelength optical a range $190-900 \mathrm{~nm}$, the measurements were carried out at room temperature.

\section{Results and discussion}

The absorption spectra of pure as well as Methyl Red and Methyl Blue doped PMMA are shown in the Fig.1. It was found that the absorption edge shifts towards higher wavelength due to doping by $\mathrm{mr}$ (red shift) and shifts towards lower wavelength due to doping by mb (blue shift).

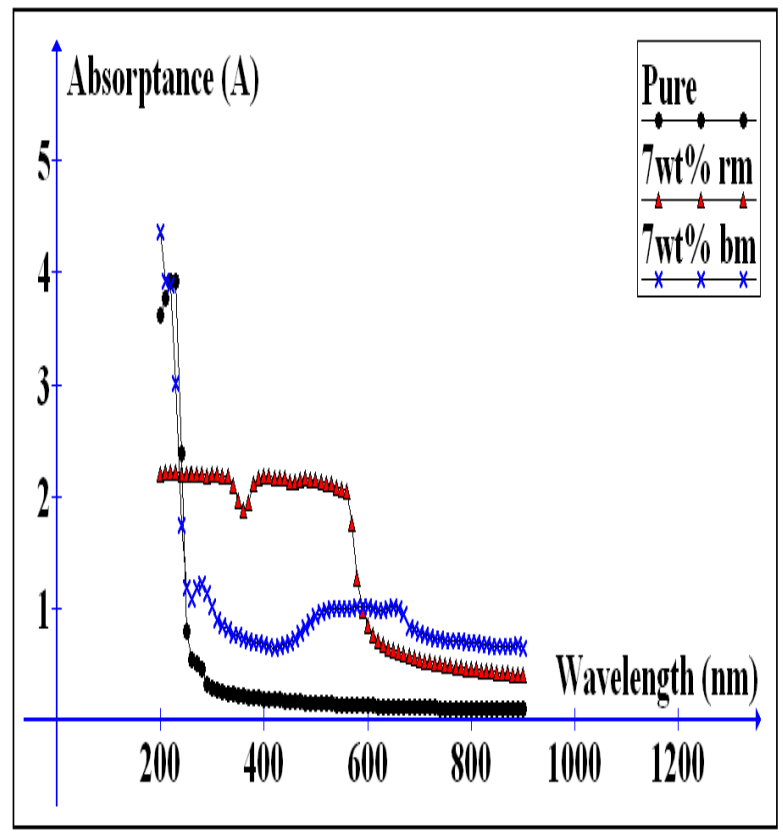

Fig.1: Absorptance of (pure and doped PMMA $7 \mathrm{wt} \% \mathrm{mr}$ and $7 \mathrm{wt} \% \mathrm{mb}$ ) samples.

The optical transmission spectra as a function of wavelength in the range of 190900nm is shown in Fig. 2. The data showed that optical transmission values of PMMA doped with mrare lower than the values of samples doped with $\mathrm{mb}$, the transmittance was decrease with doping by methyl red (mr) and methyl blue (bm), the transmittance was decrease as the doping increase.

The following relation was used to calculate the absorption coefficient $(\alpha)$ [12]:

$$
\alpha=\frac{2.303 A}{t}
$$

where (A) is the absorption and $(\mathrm{t})$ is the film thickness.

Fig.3 shows the dependency of the absorption coefficient $(\alpha)$ on the wavelength for the samples. At short wavelength, $(\alpha)$ 
takes higher value $\left(\alpha \geq 10^{4}\right) \mathrm{cm}^{-1}$ and then increases with decreasing $(\lambda)$ (increasing photon energy), and the marked increase of the absorption coefficient at higher energies may be attributed to extra transition from the bonding molecular orbit to nonbonding molecular orbit [13].

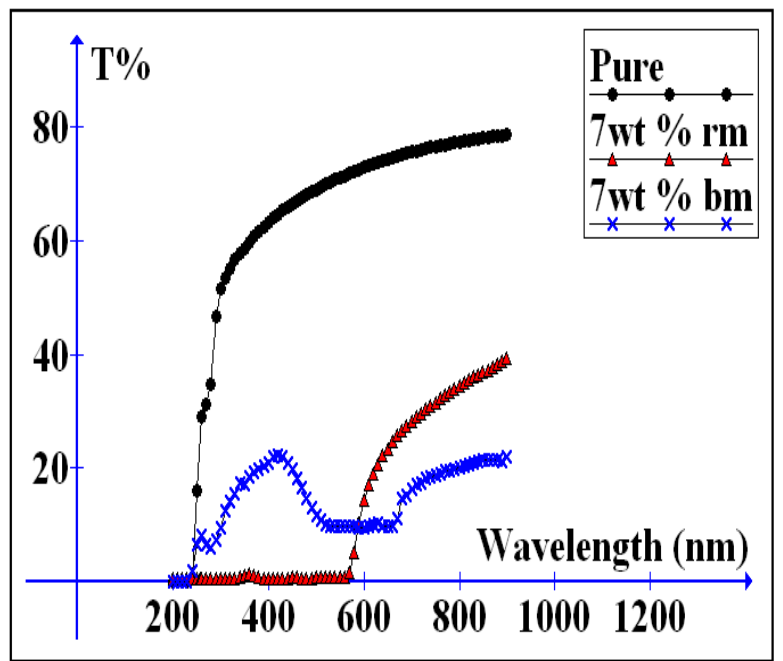

Fig. 2: Transmission spectra of pure and doped PMMA (7 wt\% $\mathrm{mr}$ and $7 \mathrm{wt} \% \mathrm{mb}$ ) samples.

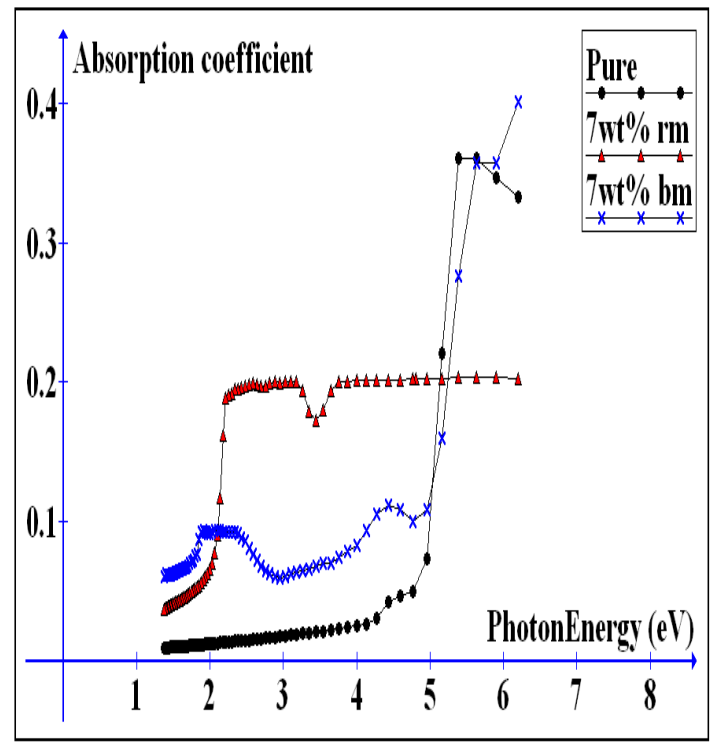

Fig. 3: Absorption coefficient of pure and doped PMMA ( 7 wt\% $\mathrm{mr}$ and 7 wt\% $\mathrm{mb}$ ) samples.

The energy band gaps of these films were calculated with the help of the absorption spectra. To determinate of the energy band gap, $(\alpha h f)^{1 / 2}$ is plotted versus (photon energy) using the relation $[14,15]$.

$\alpha \mathrm{hf}=$ const. $\left(\mathrm{hf}-\mathrm{E}_{\mathrm{g}}\right)^{\mathrm{n}}$

where $E_{\mathrm{g}}$ : the band-gap energy.

$$
\begin{aligned}
& \mathrm{h} \text { : blank constant. } \\
& \mathrm{f} \text { : frequency. }
\end{aligned}
$$

The plot of the product of absorption coefficient and photon energy $(\alpha \mathrm{hf})^{1 / 2}$ versus the photon energy at room temperature shows a linear behavior, which can be considered as an evidence for indirect allowed transition. Extrapolation of the linear portion of this curve to a point $(\alpha h f)^{1 / 2}=0$ gives the optical energy band gap $\mathrm{E}_{\mathrm{g}}$ for the pure as well as doped PMMA films. The existence and variation of optical energy gap $\mathrm{E}_{\mathrm{g}}$ with the photon energy, as the methyl red and methyl blue from $0 \%, 7 \% \mathrm{mr}$, $7 \% \mathrm{mb}$ we obtained optical energy gap was $4.68,4.20$ and $2.19 \mathrm{eV}$, in general optical energy gaps decreases with doping as shown in Fig.4.

The refractive index (n) can be determined from the reflectance $(\mathrm{R})$ using the relation [16]:

$$
n=\left(\frac{1+R}{1-R}\right)+\sqrt{\frac{4 R}{(1-R)^{2}}-k_{\circ}^{2}}
$$

where $\mathrm{k}^{\circ}$ : Extinction Coefficient.

Fig. 5 shows the variation of $\left(n^{\circ}\right)$ as function of wavelength $(\lambda)$. It is clear that $(n \circ)$ of pure PMMA decreases with $\lambda$, indeed (no) changes from doped by methyl red and methyl blue, and (no) of methyl blue higher than (methyl red).

Fig. 6 shows the variation of $\left(\mathrm{k}^{\circ}\right)$ as function of wavelength $(\lambda) . \mathrm{k}^{\circ}$ is directly proportional to the absorption coefficient as see in relation [17]:

$k_{o}=\frac{\alpha \lambda}{4 \pi}$

$\mathrm{k} \circ$ represents the imaginary part of complex refractive index and it can be defined as the 
amount of energy losing as a result of interaction between the light and the charge of medium[18].

The real dielectric constant part $\varepsilon_{\mathrm{r}}$ and imaginary dielectric constant part $\varepsilon_{\mathrm{i}}$ related to the $\mathrm{n}^{\circ}$ and $\mathrm{k}^{\circ}$ values. The $\varepsilon_{\mathrm{r}}$ and $\varepsilon_{\mathrm{i}}$ values were calculated using the form [19]:

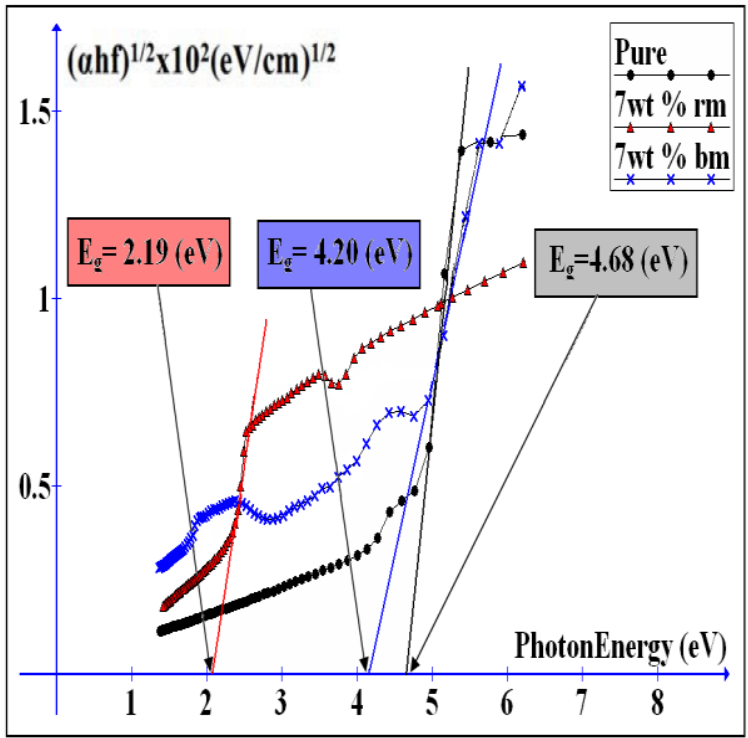

Fig. 4: Optical energy band gap of pure and doped PMMA (7 wt\% $\mathrm{mr}$ and 7 wt\% $\mathrm{mb}$ ) samples.

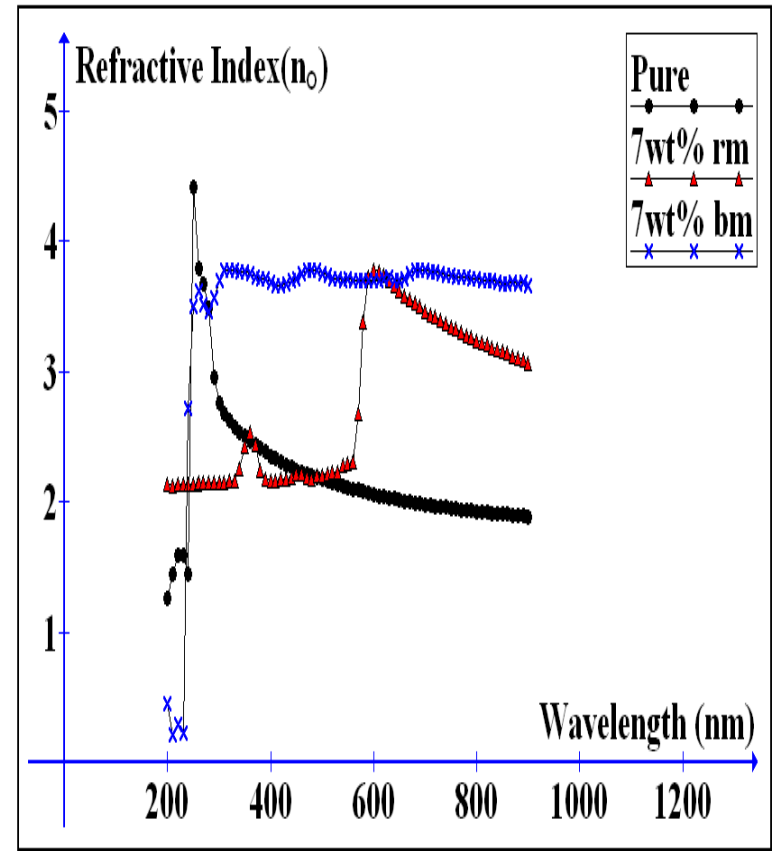

Fig. 5: Refractive index of pure and doped PMMA (7 wt\% mr and 7 wt\% $\mathrm{mb}$ ) samples.

$$
\begin{aligned}
\varepsilon_{r} & =\boldsymbol{n}_{\circ}{ }^{2}-\boldsymbol{k}_{\circ}^{2} \\
\varepsilon_{\boldsymbol{i}} & =2 \boldsymbol{n}_{\circ} \boldsymbol{k}_{\circ}
\end{aligned}
$$

the real and imaginary parts dielectric constant for pure and doped PMMA the real part of it associated with the term that how much it will slow down the speed of light in the material and imaginary part gives that how a dielectric absorb energy from electric field due to dipole motion, it was clearly seen for both $\varepsilon_{\mathrm{r}}$ and $\varepsilon_{\mathrm{i}}$ that the value of them The dielectric constants consists of real part $\varepsilon_{\mathrm{r}}$ and imaginary part $\varepsilon_{\mathrm{i}}$, the variations of them with photon energy were determined and shown in Fig.7 and 8.

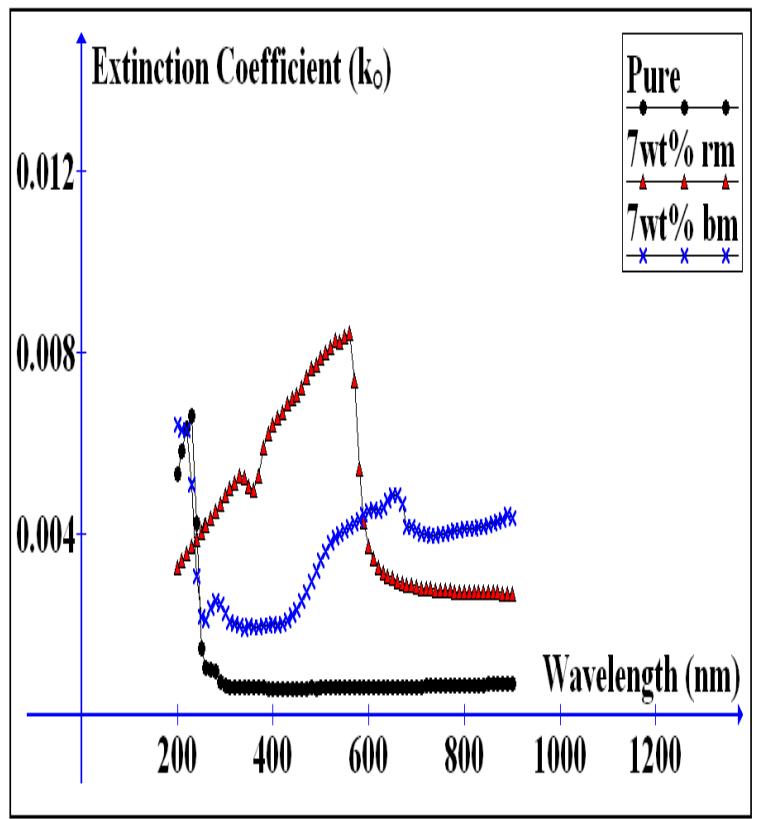

Fig. 6: Extinction coefficient of pure and doped PMMA (7 wt\% $\mathrm{mr}$ and 7 wt\% $\mathrm{mb}$ ) samples.

\section{Conclusions}

Pure PMMA and methyl red, methyl blue doped PMMA have been prepared successfully by casting method, The Absorptance data reveals that the doping affected the absorption edge as a red and blue shift in its values from $0 \%, 7 \% \mathrm{mr}$ 
and $7 \% \mathrm{mb}$ we obtained optical energy gap was $4.68,4.20$ and $2.19 \mathrm{eV}$, In general

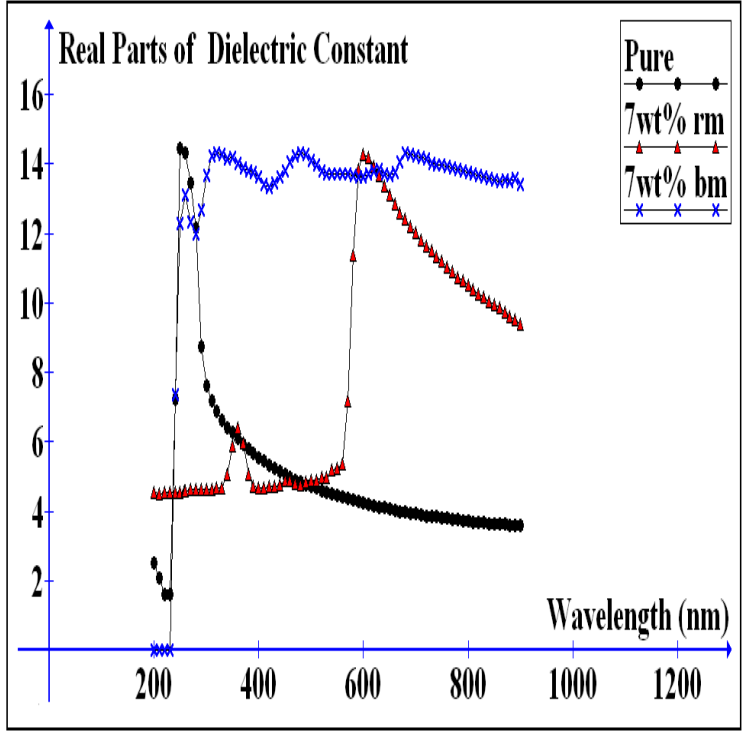

Fig. 7: $\varepsilon_{r}$ of pure and doped PMMA (7 wt\% $\mathrm{mr}$ and $7 \mathrm{wt} \% \mathrm{mb}$ ) samples.

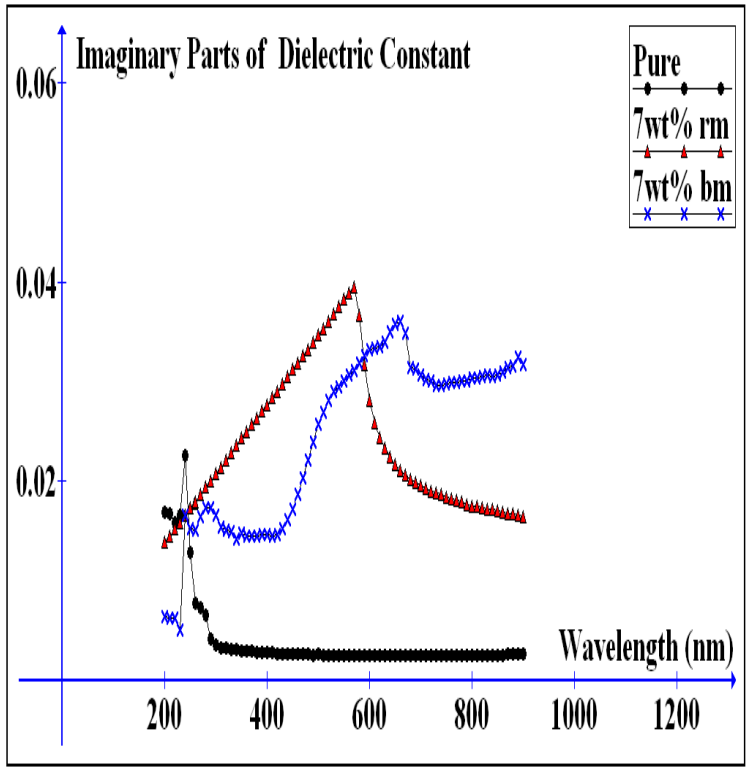

Fig. 8: $\varepsilon_{i}$ of pure and doped PMMA (7 wt\% mr and $7 \mathrm{wt} \% \mathrm{mb}$ ) samples.

\section{References}

[1] Rajkumar Thangamani, Sivasamy Palanichamy, S. Bojja and V. C. Thangavel, Polymers for Advanced Technologies, 23 (2012) 829-834.

[2] X. Lv, Z. Li, Y. Zhu, J. Zhao, G. Zhao, Ceramics International, 39 (2013) 1893- optical energy gaps decreases with doping.

1899.

[3] I. Capan, C. Tarmci, A. K. Hassan and T. Tanrisever, Materials Sciene and Engineering C, 29 (2009) 140.

[4] Melo Carpaneda, Erick Carpaneda and Carlos Augusto, Aesthetic Plastic Surgery, 36 (2012) 955-963.

[5] H. Kaczmarek and H. Chaberska, Appl. Surf. Science, 252 (2006) 8185.

[6] B. Zhang and F. D. Blum, Polym Preprints, 43 (2002) 484.

[7] X. M. Dong, Y. Luo, L. N. Xie, R. W. Fu and M. Q. Zhang, Thin Solid Films, 516 (2008) 7886.

[8] W. Caseri, Macromolecular Rapid Communicaltions, 21,11 (2000) 705.

[9] E. Kim, Y. Lee, J. Bang and K. Kim, Materials Chemistry and Physics, 134 (2012) 814-820.

[10] Osiris W. Guirguis, Manal T. H. Moselhey, J Mater Sci., 46 (2011) 57755789.

[11] M.Abdelaziz, M. M. Ghannam, Science Direct, Physica, B 405 (2010) 958-964.

[12] X.Han, R.Liu, W.Chen, and Z. Xu, Thin Solid Films, 516 (2008) 4025- 4029.

[13] K. A. M. Abd El-Kader, S. F. Abdel Hamied, A. B. Mansour, A.M.Y ElLawindy and F. El-Tantaway, Polymer Testing, 21 (2002) 847-850.

[15] J.B. Yadav, R.K. Puri, V. Puri, Applied Surface Science, 254 (2007) 1382-1388.

[16] A. Ashour, M. A. Kaid, N. Z. El-Sayed and A. A. Ibrahim, Applied Surface Science, 252 (2006) 7844-7848.

[17] A. K. Baker and P. E. Dyer, Journal Applied Physics Materials Science and Processing, 57 (1993) 543-544.

[18] Thesis, Firas Hashem Ahmed, ALMustansiriay University, (2003).

[19] S. R. Bhattacharyya, R.N. Gayen, R. Paul and A. K. Pal, Thin Solid Films, 517 (2009) 5530. 
